\title{
Very long-term durability of the edge-to-edge repair for isolated anterior mitral leaflet prolapse: Up to 21 years of clinical and echocardiographic results
}

\author{
Michele De Bonis, MD, Elisabetta Lapenna, MD, Maurizio Taramasso, MD, Giovanni La Canna, MD, \\ Nicola Buzzatti, MD, Federico Pappalardo, MD, and Ottavio Alfieri, MD
}

Objective: To assess the very long-term clinical and echocardiographic results of the edge-to-edge repair for mitral regurgitation (MR) due to isolated prolapse or flail of the anterior leaflet.

Methods: From 1991 to 2004, 139 patients (age, $54 \pm 14.4$ years; left ventricular ejection fraction $56 \% \pm 7.8 \%$, New York Heart Association class I-II in $68.9 \%$, atrial fibrillation in $20.1 \%$ ) with severe degenerative MR due to isolated segmental prolapse or flail of the anterior leaflet were treated with the EE technique combined with annuloplasty. MR had resulted from prolapse or flail of the central scallop of the anterior leaflet (A2) in 105 patients $(75.5 \%)$ and scallops A1 or A3 in $34(24.4 \%)$.

\begin{abstract}
Results: No hospital deaths occurred. At hospital discharge, MR was absent or mild in 130 patients (93.5\%) and moderate $(2+/ 4+)$ in $9(6.4 \%)$. The clinical and echocardiographic follow-up data were $97.1 \%$ complete (mean length, $11.5 \pm 3.73$ years; median, 11; longest duration, 21.5). At 17 years, the actuarial survival was $72.4 \% \pm 7.89 \%$, freedom from cardiac death was $90.8 \% \pm 4.77 \%$, and freedom from reoperation was $89.6 \% \pm 2.74 \%$. At the last echocardiographic examination, recurrence of MR grade $\geq 3+$ was documented in 17 patients $(17$ of $135,12.5 \%$ ). Freedom from MR grade $\geq 3+$ at 17 years was $80.2 \% \pm 5.86 \%$. At multivariate analysis, the predictors of MR recurrence grade $\geq 3+$ were residual MR greater than mild at hospital discharge (hazard ratio, 7.4; 95\% confidence interval, $2.5-21.2 ; P=.0001$ ) and the use of posterior pericardial rather than prosthetic ring annuloplasty, which was very close to statistical significance (hazard ratio, 2.8; $95 \%$ confidence interval, $0.9-8.7 ; P=.06$ ).
\end{abstract}

Conclusions: In patients with MR due to segmental anterior leaflet prolapse, the very long-term results of the edge-to-edge repair combined with annuloplasty were excellent. (J Thorac Cardiovasc Surg 2014;148:2027-32)

\begin{abstract}
Degenerative mitral valve regurgitation (MR) can currently be successfully repaired in expert centers in about $95 \%$ of the patients using a large array of contemporary surgical techniques. $^{1,2}$ In the presence of severe MR due to prolapse or flail of the anterior mitral leaflet (ALP), several different methods of repair have been used, including triangular resection, chordal shortening, chordal transfer, artificial chordae implantation, papillary muscle repositioning, and the edge-to-edge (EE) technique. ${ }^{3-8}$ Since 1991, at our institution, segmental prolapse of the anterior leaflet involving only 1 scallop has been preferentially corrected with a "functional" rather than an "anatomic" repair using EE approximation of the anterior and posterior leaflet at the site of the regurgitant jet. ${ }^{8}$
\end{abstract}

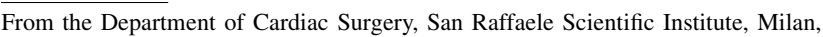
Italy.

Disclosures: Authors have nothing to disclose with regard to commercial support. Received for publication Nov 19, 2013; revisions received March 11, 2014; accepted for publication March 21, 2014; available ahead of print April 19, 2014.

Address for reprints: Michele De Bonis, MD, Department of Cardiac Surgery,

San Raffaele Scientific Institute, Via Olgettina 60, Milan 20132, Italy (E-mail: debonis.michele@hsr.it).

$0022-5223 / \$ 36.00$

Copyright $(2014$ by The American Association for Thoracic Surgery

http://dx.doi.org/10.1016/j.jtcvs.2014.03.041
}

We have previously reported the results of this technique at a median follow-up of 3.1 years. ${ }^{9}$ In the present report, we have described the long-term outcomes of EE repair combined with mitral annuloplasty in patients with severe MR due to segmental prolapse or flail of the anterior leaflet. These patients were assessed with clinical and echocardiographic follow-up performed at a median interval of 11 years ( $\leq 21.5$ years) after surgery.

\section{METHODS}

\section{Patients}

At our institution, from 1991 to December 2004, 139 patients with severe degenerative MR due to isolated segmental prolapse or flail of the anterior leaflet underwent mitral valve (MV) repair with an EE technique combined with annuloplasty. We selected this period to assess the long-term results. Moreover, for the purposes of the present study, patients with $\geq 1$ of the following conditions were not included: etiology of mitral disease other than degenerative, MV repair without annuloplasty, concomitant use of other repair techniques, associated aortic disease, or aortic or tricuspid replacement. Patients with secondary tricuspid insufficiency who underwent annuloplasty and those with associated incidental coronary artery disease or atrial septal defect were retained. The preoperative, intraoperative, and postoperative data from the hospital database and patient records were retrospectively reviewed. The institutional ethic committee approved the present study and waived individual consent for our retrospective analysis. The preoperative patient 


\author{
Abbreviations and Acronyms \\ $\mathrm{ALP}=$ anterior mitral leaflet prolapse \\ $\mathrm{EE}=$ edge-to-edge \\ $\mathrm{MR}=$ mitral valve regurgitation \\ $\mathrm{MV}=$ mitral valve
}

characteristics and some operative data are listed in Table 1. The mean patient age was $54 \pm 14.4$ years, and $68.9 \%$ of the patients were in New York Heart Association (NYHA) class I-II. The mean left ventricular ejection fraction was $56 \% \pm 7.8 \%$, and 28 patients $(20.1 \%)$ were in atrial fibrillation.

\section{Echocardiographic Study}

All patients underwent preoperative transthoracic echocardiography followed by transesophageal Doppler echocardiography. Using Carpentier's classification, ${ }^{3}$ the mechanism of MR was a type 2 lesion in all patients. The degree of MR was defined as mild $(1+/ 4+)$, moderate $(2+/ 4+)$, moderate-to-severe $(3+/ 4+)$ and severe $(4+/ 4+)$ using an integrative approach, as recommended by the current guidelines. ${ }^{10,11}$ Transesophageal echocardiography was repeated intraoperatively after the induction of general anesthesia and immediately after weaning from cardiopulmonary bypass. A transthoracic echocardiographic examination was performed at hospital discharge and during follow-up.

\section{Operative Technique}

The operation was performed through a median sternotomy in 131 patients and through a right anterior minithoracotomy in 8 . After the incision was performed in the interatrial groove, the MV was approached through the left atrium and carefully inspected to identify the lesion described using transesophageal Doppler echocardiography. The correction of MR was performed using the EE technique, as previously described. ${ }^{8}$ In 105 patients $(75.5 \%)$ with prolapse or flail of A2, the EE suture was placed in (or close to) the central portion of the leaflets (double orifice repair). In 34 patients $(24.5 \%)$ with A1 or A3 lesions, the approximation of the free edges of the leaflets was performed laterally, in continuity with the commissure (paracommissural repair). All patients included in the present series had undergone concomitant annuloplasty. A prosthetic ring was implanted in 128 patients (92\%), and a posterior annuloplasty with autologous pericardium was preferred in 11 $(8 \%)$. The final valve area was occasionally measured using Hegar dilators to exclude mitral stenosis. The competence of the valve was checked by forceful saline injection into the left ventricle. In 37 patients (26.6\%), other cardiac procedures were associated (Table 1). The vast majority were tricuspid annuloplasty, radiofrequency ablation of atrial fibrillation, and myocardial revascularization. After weaning from cardiopulmonary bypass, a transesophageal Doppler echocardiographic examination was routinely performed to assess the final result of the repair and measure the MVarea. A global valve area of $2.5 \mathrm{~cm}^{2}$ was considered satisfactory for normal size patients.

\section{Follow-up}

Follow-up was performed through outpatient visits and transthoracic echocardiographic examinations at our institution or by telephone interviews with the patient and referring cardiologist. Clinical and echocardiographic information was available for 135 patients $(97.1 \%$ complete). Four patients were lost to follow-up. The mean length of follow-up was $11.5 \pm 3.73$ years (median, 11 years; interquartile range, 9.2-13.6). The longest follow-up duration reached 21.5 years.

\section{Statistical Analysis}

Calculations were performed using the Statistical Package for Social Sciences, version 11.5 (SPSS, Inc, Chicago, Ill) for Windows (Microsoft,
Redmond, Wash). Data are presented as the mean \pm standard deviation or median and interquartile range. For continuous, normally distributed data, comparisons between the 2 groups were performed using Student's $t$ test for unpaired samples, as indicated. If the continuous data were not normally distributed, the Mann-Whitney $U$ test or Wilcoxon signed rank test was used for independent or related samples, respectively. Comparisons of the categorical variables were performed using the chi-square test and Fisher's exact test. The NYHA functional class and MR grade were treated as ordinal variables and compared using the Wilcoxon signed rank test (related samples) or Mann-Whitney $U$ test (independent samples). Survival and freedom from events were evaluated using Kaplan-Meier analysis. For actuarial estimates, the data are presented as the mean \pm standard error. Univariate analysis of the predictors of recurrence of MR grade $\geq 3+$ was performed using Cox proportional hazards regression, and variables with $P<.1$ were entered into a multivariable model.

\section{RESULTS}

\section{Mortality and Morbidity}

No hospital deaths occurred. The postoperative course was rather smooth for the vast majority of patients. Early and late complications are listed in Table 2. Sixteen patients died after hospital discharge. The cause of death was cardiac related in 7 . The causes of late mortality are summarized in Table 3. At 17 years, the actuarial overall survival was $72 \% \pm 7.89 \%$ (Figure 1) and freedom from cardiac death was $90 \% \pm 4.73 \%$ (Figure 2).

\section{Echocardiographic and Clinical Results}

All patients underwent a control transesophageal echocardiographic examination in the operating room followed by transthoracic echocardiography at discharge. At hospital discharge, MR was absent or mild in 130 patients $(93.5 \%)$ and moderate $(2+/ 4+)$ in $9(6.4 \%)$.

At least 1 transthoracic echocardiogram was available at follow-up for 135 patients. At the last echocardiogram, the mean MV area was $2.9 \pm 0.46 \mathrm{~cm}^{2}$ (median, 3; range, 1.8-4). Clinically relevant mitral stenosis was never detected. MR was absent in 15 patients $(11.1 \%)$, mild in $85(62.9 \%)$, moderate in $18(13.3 \%)$, moderate-to-severe in $4(2.9 \%)$, and severe in $13(9.6 \%)$. Overall, 17 patients $(12.5 \%)$ had recurrent MR grade $\geq 3+$ at follow-up. The freedom from MR grade $3+$ or $4+$ at 17 years was $80.2 \% \pm 5.86 \%$. Preoperative factors such as age, gender, atrial fibrillation, NYHA class, and LV function were not identified as predictors of MR recurrence. Similarly, the site of the EE suture (commissural vs central) had no influence on repair failure. Patients with more complex cases requiring cardiac operations in addition to MV repair did not have a greater rate of recurrent $M R$ grade $\geq 3+$ than those who had undergone MV reconstruction alone (Table 4). On multivariate analysis, the only independent predictor of MR grade $\geq 3+$ recurrence was residual MR greater than mild at hospital discharge (hazard ratio [HR], 7.4; 95\% confidence interval $[\mathrm{CI}], 2.5-21.2 ; P=.0001$ ). However, the use of posterior pericardial rather than 
TABLE 1. Baseline characteristics of the patients and operative data

\begin{tabular}{lc}
\hline \multicolumn{1}{c}{ Characteristic } & Value \\
\hline Patients & 139 \\
Age (y) & $54 \pm 14.4$ \\
Male gender & $79(56.8)$ \\
NYHA class & \\
I & $50(35.9)$ \\
II & $46(33)$ \\
III & $42(30.2)$ \\
IV & $1(0.7)$ \\
AF at presentation & $28(20.1)$ \\
EF (\%) & $56 \pm 7.8$ \\
Ring used for mitral annuloplasty & \\
St Jude Séguin & $92(66.1)$ \\
Carpentier-Edwards classic & $25(17.9)$ \\
Flexible Duran & $6(4.3)$ \\
Flexible Sovering & $3(2.1)$ \\
Flexible St Jude Tailor & $2(1.4)$ \\
Autologous pericardium & $11(7.9)$ \\
Mean annuloplasty ring size & $34.6 \pm 3.2$ \\
Associated procedures & \\
ASD correction & $4(2.8)$ \\
CABG & $10(7.1)$ \\
Tricuspid annuloplasty & $15(10.7)$ \\
Radiofrequency ablation of AF & $12(8.6)$ \\
\hline Data presented as mean \pm standard deviation or $\mathrm{n}(\%) . N Y H A$, New York Heart \\
Association; $A F$, atrial fibrillation; $E F$, ejection fraction; ASD, atrial septal defect; \\
$C A B G$, coronary artery bypass grafting. &
\end{tabular}

prosthetic ring annuloplasty was very close to statistical significance (HR, 2.8; 95\% CI, 0.9-8.7; $P=.06$ ).

A significant clinical improvement was also documented. NYHA class I was present in 94 patients $(69.6 \%)$,

TABLE 2. Postoperative and late complications

\begin{tabular}{lc}
\hline \multicolumn{1}{c}{ Variable } & $\mathbf{n}(\%)$ \\
\hline Postoperative morbidity & \\
Low output syndrome & $2(1.4)$ \\
Prolonged ventilatory support $(>48 \mathrm{~h})$ & $5(3.5)$ \\
Re-exploration for bleeding & $3(2.2)$ \\
Pericardial effusion & $1(0.7)$ \\
Pacemaker implantation & $1(0.7)$ \\
Sternal rewiring & $2(1.4)$ \\
Late complications & \\
Rhythm disturbances requiring permanent pacemaker & $4(2.9)$ \\
Persistent or permanent AF treated with percutaneous & $3(2.2)$ \\
$\quad$ RF ablation & \\
Endocarditis & $1(0.7)$ \\
Hemolysis (mitral ring dehiscence) & $1(0.7)$ \\
Stroke & $2(1.4)^{*}$ \\
Congestive heart failure & $3(2.1)$ \\
Aortic dissection & $1(0.7)$ \\
Pericarditis & $2(1.4)$ \\
Myocardial infarction & $1(0.7)$ \\
Minor gastrointestinal bleeding & $1(0.7)$ \\
PTCA stenting for angina & $1(0.7)$ \\
\hline$A F$, Atrial fibrillation; $R F$, radiofrequency; PTCA, percutaneous & transluminal \\
coronary angioplasty. *One minor and one major cerebral hemorrhage. &
\end{tabular}

TABLE 3. Cause of late death

\begin{tabular}{lc}
\hline \multicolumn{1}{c}{ Variable } & Patients (n) \\
\hline Cardiac & 7 \\
Acute aortic dissection & 1 \\
Sudden death & 2 \\
Cerebral hemorrhage & 1 \\
Myocardial infarction & 1 \\
Unknown & 2 \\
Noncardiac & 9 \\
Malignancy & 4 \\
Gastrointestinal bleeding & 1 \\
Cirrhosis & 1 \\
Amyotrophic lateral sclerosis & 1 \\
Hip fracture & 1 \\
Bowel occlusion & 1 \\
Overall total & 16 \\
\hline
\end{tabular}

NYHA class II in $35(25.9 \%)$ and NYHA class III in $6(4.4 \%)$ postoperatively $(P=.0001$ compared with preoperative values).

\section{Reoperation}

All 13 patients $(9.6 \%)$ who had developed severe MR underwent reoperation 1 month to 9 years after the initial repair. The other 4 patients $(2.9 \%)$ with moderate to severe MR did not undergo reoperation. All patients requiring reoperation had undergone double orifice repair for A2 prolapse or flail due to either chordal rupture or elongation. In 1 patient, the cause of recurrent MR was mitral endocarditis and in 1 was mitral ring dehiscence (SJM Séguin Semi-Rigid Ring, no. 36, St Jude Medical, St Paul, Minn), leading to hemolysis and recurrent MR.

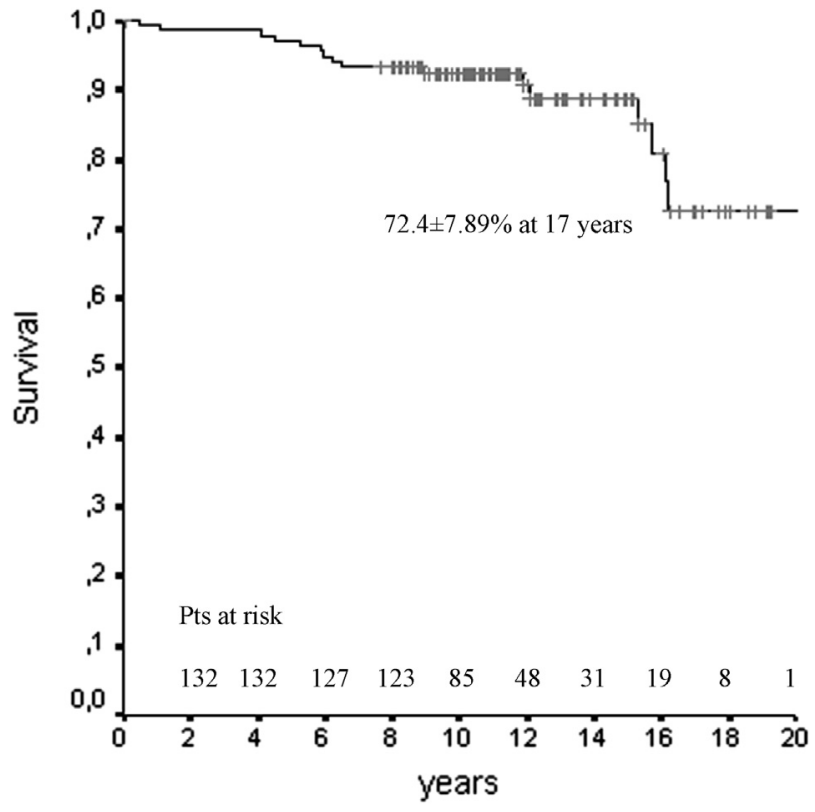

FIGURE 1. Actuarial overall survival. Pts, Patients. 


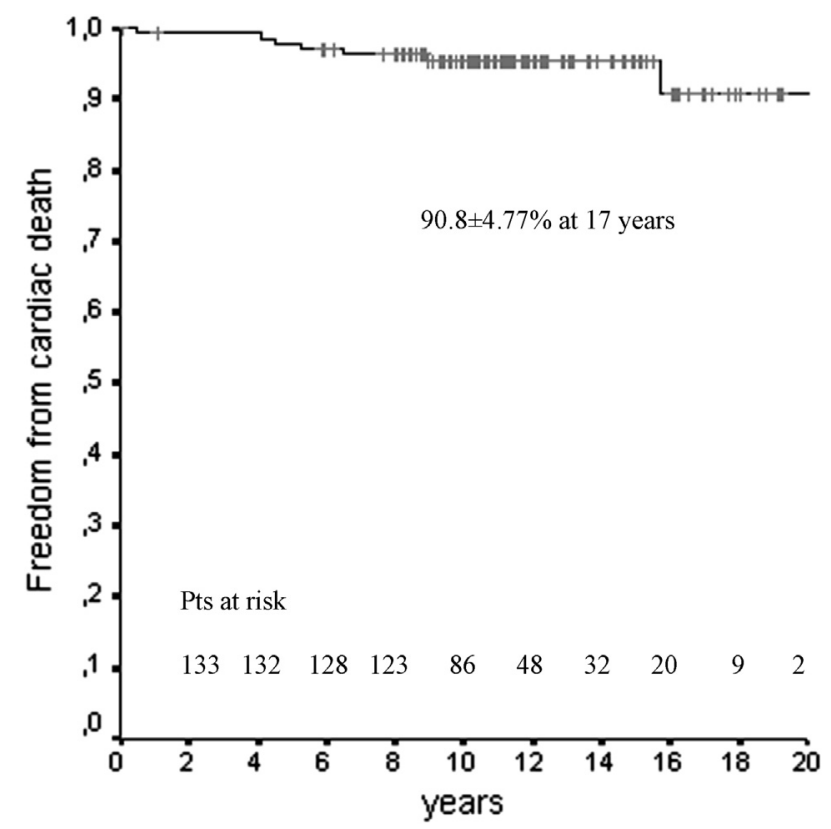

FIGURE 2. Actuarial freedom from cardiac death. Pts, Patients.

In the remaining patients, new regurgitant jets from 1 or both mitral orifices were reported and were usually attributed to new prolapse. Only in 1 of them was the mechanism of recurrent MR restricted motion due to leaflet fibrosis. Of the 13 patients, $5(38.4 \%)$ already had moderate residual MR at hospital discharge. All 13 patients underwent MV replacement (5 at our institution and 8 at other centers). Freedom from reoperation at 17 years was $89.6 \% \pm 2.74 \%$ (Figure 3 ). The use of pericardial annuloplasty (HR, 3.5; 95\% CI, 0.9-12.7; $P=.05$ ) and the presence of residual MR $>1+$ at discharge (HR, 11.6; $95 \%$ CI, 3.7-35.8; $P=.0001)$ were identified as significant predictors of reoperation on univariate analysis. The multivariate analysis confirmed residual $\mathrm{MR}>1+$ at discharge as the only independent predictor of this event

TABLE 4. Predictors of recurrence of mitral regurgitation grade $\geq 3+$

\begin{tabular}{|c|c|c|c|c|c|c|}
\hline \multirow[b]{2}{*}{ Variable } & \multicolumn{4}{|c|}{ Univariate } & \multicolumn{2}{|c|}{ Multivariate } \\
\hline & HR & $\mathbf{9 5} \%$ CI & $\begin{array}{c}P \\
\text { value } \\
\end{array}$ & HR & $95 \%$ CI & $\begin{array}{c}P \\
\text { value } \\
\end{array}$ \\
\hline Age & 1.0 & $0.97-1.04$ & .2 & - & - & - \\
\hline Female gender & 1 & $0.4-2.8$ & .8 & - & - & - \\
\hline LVEF & 1 & $0.9-1.1$ & .5 & - & - & - \\
\hline NYHA $>2$ & 2.1 & $0.8-5.6$ & .1 & - & - & - \\
\hline $\mathrm{AF}$ & 1.2 & $0.3-4$ & .7 & - & - & - \\
\hline Paracommissural EE vs DO & 0.3 & $0.07-1.5$ & .1 & - & - & - \\
\hline Pericardial annuloplasty & 2.9 & $0.9-9.2$ & .06 & 2.8 & $0.9-8.7$ & .06 \\
\hline Associate procedures & 1.3 & $0.4-3.7$ & .5 & - & - & - \\
\hline$\underline{\text { MR grade }}>1+$ at discharge & 7.4 & 2.6-21.5 & .0001 & 7.4 & $2.5-21.2$ & .0001 \\
\hline
\end{tabular}

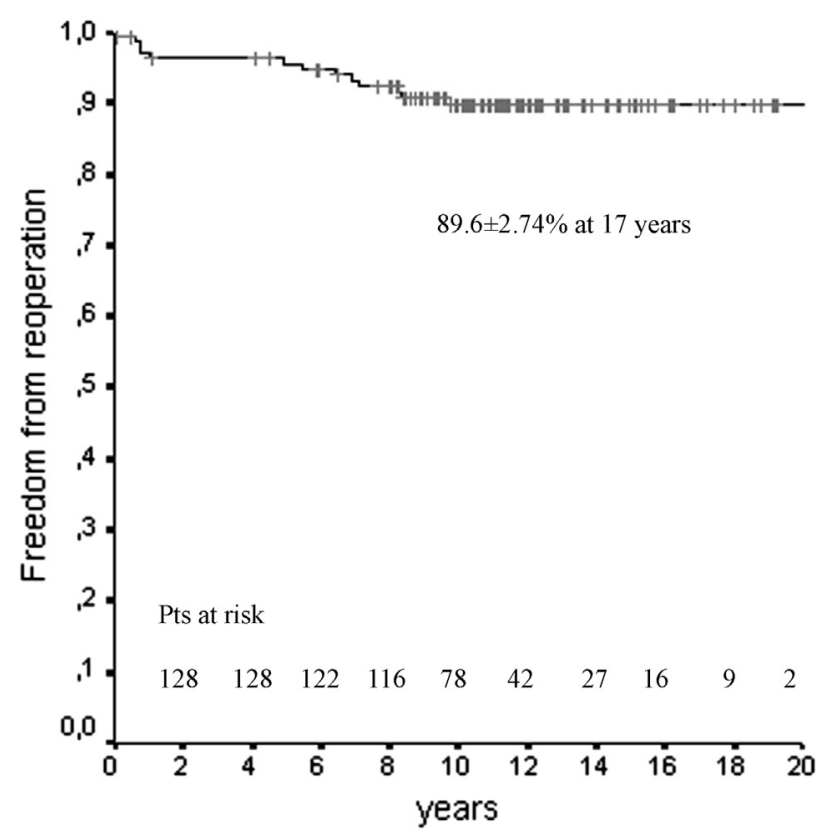

FIGURE 3. Actuarial freedom from reoperation. Pts, Patients.

(HR, 10.7; 95\% CI, 3.4-35.5; $P=.0001)$. Freedom from reoperation and MR grade $3+$ or $4+$ at 17 years was $80 \% \pm 5.8 \%$ (Figure 4 ).

\section{DISCUSSION}

The main finding of the present study was that the EE technique, combined with annuloplasty, provides excellent clinical and echocardiographic long-term results in patients

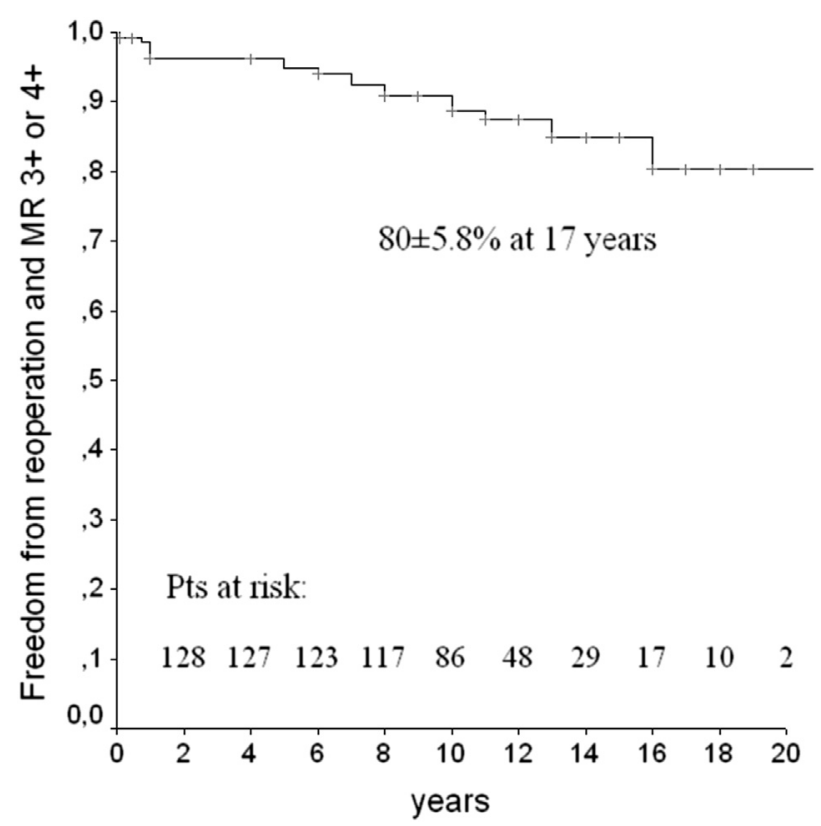

FIGURE 4. Actuarial freedom from reoperation and mitral regurgitation grade (MR) $3+$ or $4+$. Pts, Patients. 
with degenerative MR due to isolated segmental prolapse of the anterior leaflet. Unlike posterior leaflet prolapse, which can be repaired with excellent outcomes, ${ }^{12}$ ALP has been associated with a decreased repair rate ${ }^{1,13,14}$ and greater MR recurrence, even in experienced centers. ${ }^{15,16}$ Gillinov and colleagues ${ }^{1}$ reported at 5 years of follow-up, a rate of MR grade $\geq 2+$ recurrence of $19 \%$ for isolated anterior leaflet repair compared with $13 \%$ for posterior repair $(P=.03)$. Suri and colleagues ${ }^{13}$ reported a linearized risk of reoperation annually of $1.64 \%$ for anterior leaflet repair, significantly greater than the $0.5 \%$ annually for posterior leaflet repair, although the rate of MR recurrence at follow-up was not reported.

David and colleagues, ${ }^{17}$ in a large series of 840 patients with long-term follow-up who had undergone mitral repair, including 93 patients with isolated ALP (11\% of the total), reported a freedom from moderate or severe MR at 20 years of $69.2 \%$. The precise rate of recurrence in the subgroup with isolated anterior repair was not reported. However, the investigators found that isolated ALP was an independent predictor of MR recurrence on multivariate analysis. ${ }^{17}$

Several different surgical techniques have been described to treat ALP. ${ }^{3-8,18}$ At our institution, this lesion has been preferentially corrected by EE approximation of the anterior and posterior leaflet at the site of the regurgitant jet. ${ }^{8}$ We have previously reported the results of this technique at a median follow-up of 3.1 years. ${ }^{9}$ In the present study, we focused on the late clinical and echocardiographic outcomes of this approach at a median interval of 11 years $(\leq 21.5$ years) after surgery.

To minimize the presence of confounding variables, we specifically included in the present series only adult patients with degenerative MR due to segmental prolapse of the anterior leaflet, who had been treated exclusively with the EE technique followed by annuloplasty. The early results were excellent, with no hospital mortality. Late mortality, to the best of our knowledge, was unrelated to the technique of repair. Just as in many other series of patients treated with MV reconstruction, ${ }^{15,17,19}$ postoperative morbidity and the incidence of late complications were low. Overall survival and freedom from cardiac death were very satisfactory and at least comparable to those described in other series with a similar follow-up length. ${ }^{16-20}$ Our $90 \%$ freedom from reoperation at 17 years was excellent and was within the range reported in published studies by other groups using conventional repair techniques and with a duration of follow-up ranging from 10 to 20 years. ${ }^{16,19,20}$

One strength of our study was that the predictability of the EE technique was demonstrated, not only by the low incidence of reoperations, but also by the findings from the echocardiographic examinations, which were available for $97.1 \%$ of the patients at follow-up. Compared with the results obtained at midterm, ${ }^{9}$ a greater number of repair failures were documented, as expected, with increasing follow-up length. Nevertheless, the overall recurrence of significant MR remained low, considering that ALP has always been identified as an important risk factor for recurrent MR after MV repair. ${ }^{17}$ The only independent predictor of recurrence of MR grade $\geq 3+$ was the presence of residual MR greater than mild at hospital discharge. Of 9 patients who had had a suboptimal immediate result, 5 $(55.5 \%)$ required reoperation, confirming the importance of a perfectly competent $\mathrm{MV}$ at the end of the reconstructive procedure. The use of posterior pericardial, rather than prosthetic ring annuloplasty, was very close but did not reach statistical significance as a risk factor for recurrent MR $(P=.06)$. In the few patients for whom the cause of MR recurrence could be established, it had usually resulted from progression of the degenerative disease, with the occurrence of new prolapsing or flailing lesions in correspondence with 1 of the 2 orifices of the EE repair.

From a clinical viewpoint, an important improvement was documented during follow-up, with $>95 \%$ of the patients in NYHA functional class I or II. In contrast, before surgery, about one third were in functional class III or IV. Unlike other repair methods, the EE technique consists of suturing both leaflets together, apparently challenging the fundamental surgical concepts of MV repair and resulting in a number of questions about the risk of inducing mitral stenosis, the degree of impairment of mitral leaflet motion, and the overall long-term durability. We have already demonstrated that, if properly applied, this "functional" rather than "anatomic" repair does not cause any significant restriction both at rest and during exercise, ${ }^{21}$ as confirmed by the mean residual MV area and the excellent clinical condition of the patients. The lack of stenosis was not surprising, given the pliability of leaflet tissue in patients with degenerative disease. The excellent durability observed in our series would seem to confirm that the supposed drawbacks and risks of this technique are more theoretical than practical. Nevertheless, we recognize that, in presence of extended ALP, involving $>1$ scallop, the EE technique alone might not be sufficient to obtain a perfectly competent MV, because a long suture would be required and mitral stenosis would likely be created. In those circumstances, other techniques should be preferred, or artificial chordae should be added to the EE repair to eliminate incompetence, without excessively reducing the MV area.

\section{Study Limitations}

All the well-known limitations of every retrospective study apply to the present series. Moreover, because many patients had undergone an echocardiographic examination performed at other institutions, we could not exclude that the rate of recurrent MR in those cases might have been underestimated. However, that would seem rather unlikely because of the consistency between the good 
echocardiographic late outcomes reported and the very satisfactory clinical conditions described by the patients. In addition, no consistent data were available for $\mathrm{LV}$ dimensions, right ventricular function, and systolic pulmonary artery pressure at follow-up. Therefore, they could not be analyzed and compared with the preoperative values. Another study limitation was that the causes of recurrent MR remained unknown for most patients, because they were followed up or underwent reoperation at other institutions. Finally, the present study included a selected group of patients with degenerative MR due to ALP treated with a double orifice repair combined with annuloplasty. The results reported from our series, therefore, should not be extended to patients who underwent a double orifice technique without concomitant annuloplasty or patients with MR due to etiologies other than degenerative. Also, they should not be extended to patients with leaflet prolapse involving $>1$ scallop.

\section{CONCLUSIONS}

Our clinical and echocardiographic data have confirmed that double-orifice MV repair, combined with annuloplasty, provides excellent long-term results in patients with degenerative MR in the setting of segmental ALP. An immediate perfect result is essential to achieve optimal late durability.

\section{References}

1. Gillinov AM, Cosgrove DM, Blackstone EH, Diaz R, Arnold JH, Lytle BW, et al. Durability of mitral valve repair for degenerative disease. J Thorac Cardiovasc Surg. 1998;111:734-43.

2. Castillo JG, Anyanwu AC, Fuster V, Adams DH. A near 100\% repair rate for mitral valve prolapse is achievable in a reference center: implications for future guidelines. J Thorac Cardiovasc Surg. 2012;144:308-12.

3. Carpentier A. Cardiac valve surgery: the French correction. J Thorac Cardiovasc Surg. 1983;86:323-7.

4. Salati M, Moriggia S, Scrofani R, Santoli C. Chordal transposition for anterior mitral prolapse: early and long-term results. Eur J Cardiothorac Surg. 1997; 11:268-73.

5. Smedira NG, Selman R, Cosgrove DM, McCarthy PM, Lytle BW, Taylor PC, et al. Repair of anterior leaflet prolapse: chordal transfer is superior to chordal shortening. J Thorac Cardiovasc Surg. 1996;112:287-91.
6. David TE. Replacement of chordae tendineae with expanded polytetrafluoroethylene sutures. J Card Surg. 1989;4:286-90.

7. Zussa C, Polesel E, Rocco F, Valfrè C. Artificial chordae in the treatment of anterior mitral leaflet pathology. Cardiovasc Surg. 1997;5:125-8.

8. Alfieri O, Maisano F. An effective technique to correct anterior mitral leaflet prolapse. J Card Surg. 1999;14:468-70.

9. De Bonis M, Lorusso R, Lapenna E, Kassem S, De Cicco G, Torracca L, et al. Similar long-term results of mitral valve repair for anterior compared with posterior leaflet prolapse. J Thorac Cardiovasc Surg. 2006;131:364-70.

10. Lancellotti P, Moura L, Pierard LA, Agricola E, Popescu BA, Tribouilloy C, et al; European Association of Echocardiography. European Association of Echocardiography recommendations for the assessment of valvular regurgitation. Part 2: mitral and tricuspid regurgitation (native valve disease). Eur J Echocardiogr. 2010;11:307-32.

11. Vahanian A, Alfieri O, Andreotti F, Antunes MJ, Barón-Esquivias G, Baumgartner H, et al; Joint Task Force on the Management of Valvular Heart Disease of the European Society of Cardiology (ESC); European Association for Cardio-Thoracic Surgery (EACTS). Guidelines on the management of valvular heart disease (version 2012). Eur Heart J. 2012;33: 2451-96.

12. Johnston DR, Gillinov AM, Blackstone EH, Griffin B, Stewart W, Sabik JF III, et al. Surgical repair of posterior mitral valve prolapse: implications for guidelines and percutaneous repair. Ann Thorac Surg. 2010;89:1385-94.

13. Suri RM, Schaff HV, Dearani JA, Sundt TM III, Daly RC, Mullany CJ, et al. Survival advantage and improved durability of mitral repair for leaflet prolapse subsets in the current era. Ann Thorac Surg. 2006;82:819-26.

14. Seeburger J, Borger MA, Doll N, Walther T, Passage J, Falk V, et al. Comparison of outcomes of minimally invasive mitral valve surgery for posterior, anterior and bileaflet prolapse. Eur J Cardiothorac Surg. 2009;36:532-8.

15. Castillo JG, Anyanwu AC, El-Eshmawi A, Adams DH. All anterior and bileaflet mitral valve prolapse are repairable in the modern era of reconstructive surgery. Eur J Cardiothorac Surg. 2014;45:139-45.

16. David TE, Armstrong S, Ivanov J. Chordal replacement with polytetrafluoroethylene sutures for mitral valve repair: a 25-year experience. J Thorac Cardiovasc Surg. 2013;145:1563-9.

17. David TE, Armstrong S, McCrindle BW, Manlhiot C. Late outcomes of mitral valve repair for mitral regurgitation due to degenerative disease. Circulation. 2013;127:1485-92.

18. Dreyfus G, Al Ayle N, Dubois C, de Lentdecker P. Long term results of mitral valve repair: posterior papillary muscle repositioning versus chordal shortening. Eur J Cardiothorac Surg. 1999;16:81-7.

19. Braunberger E, Deloche A, Berrei A, Abdallah F, Celestin JA, Meimoun P, et al. Very long-term results (more than 20 years) of valve repair with Carpentier's techniques in nonrheumatic mitral valve insufficiency. Circulation. 2001; 104(Suppl I):I-8-I11.

20. Gillinov AM, Blackstone EH, Alaulaqi A, Sabik JF III, Mihaljevic T, Svensson LG, et al. Outcomes after repair of the anterior mitral leaflet for degenerative disease. Ann Thorac Surg. 2008;86:708-17.

21. Agricola E, Maisano F, Oppizzi M, De Bonis M, Torracca L, La Canna G, et al. Mitral valve reserve in double-orifice technique: an exercise echocardiographic study. J Heart Valve Dis. 2002;11:637-43. 